\title{
Mycobacterium tuberculosis
}
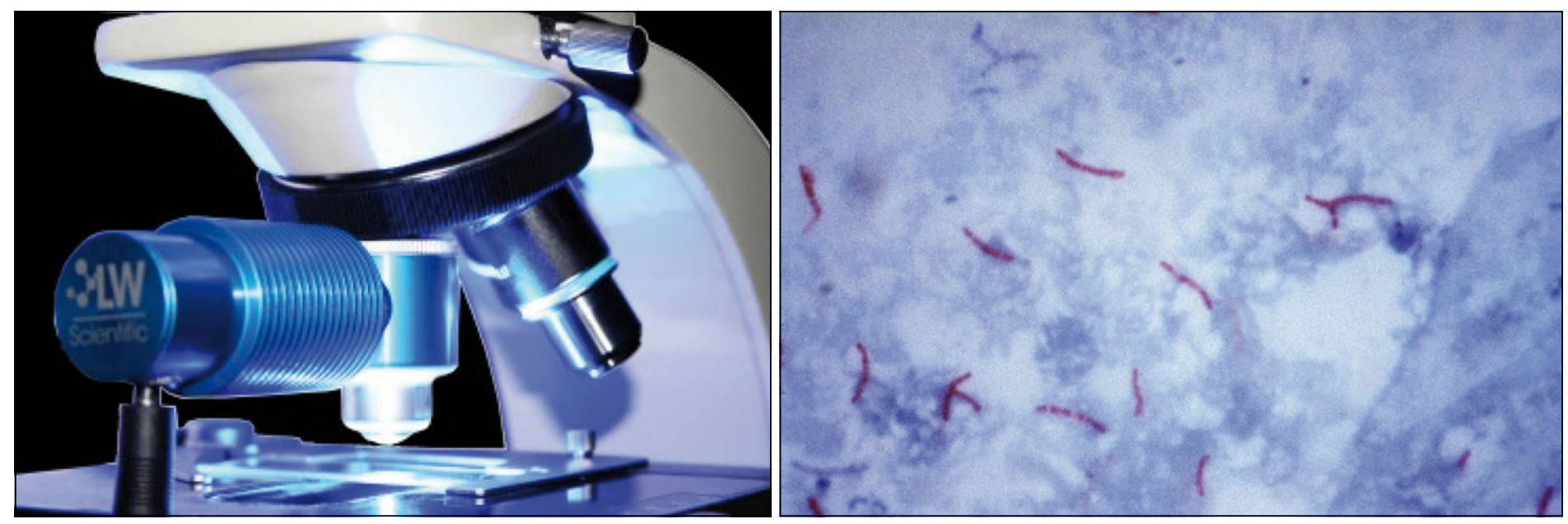

Figura 1. Lector de fluorescencia acoplado a microscopía óptica para lectura rápida de baciloscopias.

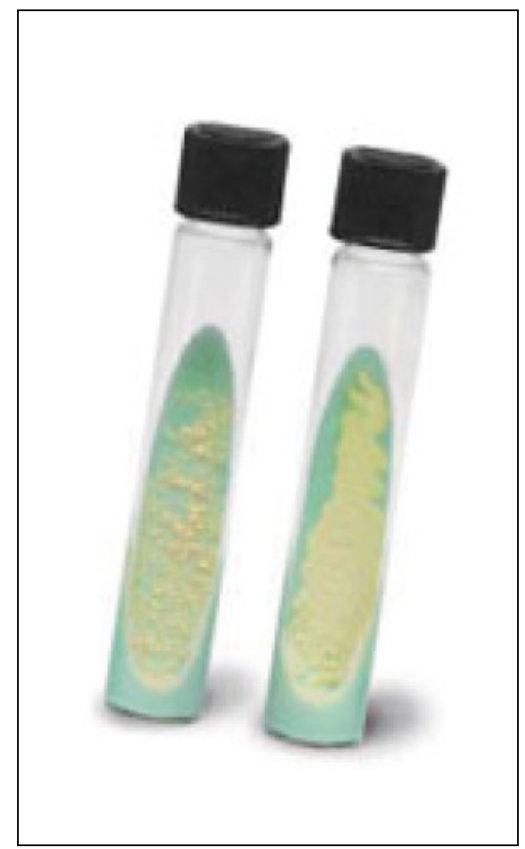

Figura 2. Medios de cultivos comerciales. 


\section{Retrato Microbiológico}

\section{Mycobacterium tuberculosis}

El género Mycobacterium está conformado por bacilos aerobios estrictos de lento crecimiento. Su pared celular contiene una estructura de peptidoglicano y ácido micólico, la que le confiere la resistencia al alcohol ácido (BAAR).

Para su estudio, la muestra debe ser representativa, evitando su contaminación con la microbiota comensal. Para la digestión/descontaminación se recomienda actualmente emplear $\mathrm{N}$-acetil cisteína. Posteriormente se realiza una concentración por centrifugación, crítica para facilitar la observación microscópica de la muestra en un frotis con tinción de Ziehl Neelsen. Se pueden agregar dispositivos externos de fluorescencia para disminuir el tiempo de lectura. El agar Löwenstein-Jensen (LJ) es el medio de elección para muestras muy contaminadas; su principal limitante es la demora en el crecimiento (mayor a un mes). Medios de crecimiento rápido como el agar 7H10 de Middlebrook permiten la recuperación 10 a 15 días antes que con el medio LJ, observando las colonias con lupa. Los medios líquidos utilizan incubadores con lectura láser, detectando crecimiento antes de 15 días en muestras con baciloscopias positivas y antes de 30 días si están negativas. Las técnicas de biología molecular son el estándar de oro en el diagnóstico, disponibles en laboratorios de referencia del país.

\section{Referencias}

1. Murray P. Microbiología Médica, sexta edición.

2. González A P. Optimización del diagnóstico microbiológico en infecciones por mycobacterias. Rev. Chil. Enf. Respir 2004; 20 (3): 182-5.

Maggie Vecchiola $\boldsymbol{H}$.

Hospital San José, Universidad de Santiago, Chile maggiev.vecchiola@redsalud.gov.cl

Una versión in extenso de este Retrato Microbiológico puede encontrarse en www.sochinf.cl 